\title{
Polycythemia and Hb Coimbra [beta 99 (G1) Asp $\rightarrow$ Glu] in Brazil
}

André Fattori ${ }^{1}$, Elza Miyuki Kimura ${ }^{2}$, Dulcinéia Martins de Albuquerque ${ }^{1}$, Satie Hatsushika Ogo $^{3}$, Graziela Renata Stoppa $^{3}$, Juliana Touquinha Martins ${ }^{1}$, Carmen Silvia Passos Lima ${ }^{1}$, Sara Terezinha Ollala Saad ${ }^{1}$, Fernando Ferreira Costa $^{1}$ and Maria de Fátima Sonati ${ }^{2}$

${ }^{1}$ Universidade Estadual de Campinas, Centro de Hematologia e Hemoterapia, Campinas, SP, Brazil.

${ }^{2}$ Universidade Estadual de Campinas, Faculdade de Ciências Médicas, Departamento de Patologia Clínica, Campinas, SP, Brazil.

${ }^{3}$ Universidade Estadual de Campinas, Instituto de Biologia, Departamento de Bioquímica, Campinas, SP, Brazil.

\begin{abstract}
We report the clinical and laboratory findings concerning three unrelated Brazilian patients investigated for polycythemia, whose definitive diagnosis could only be established after the presence of $\mathrm{Hb}$ Coimbra (B99 Asp $\rightarrow$ Glu) was demonstrated. This illustrates the importance of properly investigating hereditary hemoglobinopathies in cases of erythrocytosis because in some populations variants with high oxygen affinity may be more frequent than expected but go undetected when conventional electrophoresis is used as the sole detection procedure.
\end{abstract}

Key words: polycythemia, erythrocytosis, Hb Coimbra, beta-globin gene.

Received: January 10, 2005; Accepted: September 19, 2005.

Some rare structural hemoglobin $(\mathrm{Hb})$ variants have been reported to be associated with functional abnormalities such as high oxygen affinity and a left shift in the $\mathrm{Hb}$-oxygen dissociation curve, leading to tissue hypoxia and compensatory erythrocytosis (Bunn and Forget, 1986). At present, $84 \mathrm{Hb}$ variants with high oxygen affinity have been documented, 77 of which contain $\beta$-chain residue replacements (Globin Gene Server Web Site, http://globin. cse.psu.edu). The majority of these variants have substitutions at one of the three crucial regions for $\mathrm{Hb}$ stability and function, the $\alpha_{1} \beta_{2}$ interface, the $\beta$ chain $C$-terminal end and the 2,3-DPG binding site (Bunn and Forget, 1986; http://globin.cse.psu.edu). A particular mutation at codon 99 of the $\beta$-globin gene (GAT $\rightarrow$ GAA) results in the replacement of aspartic acid for glutamic acid in the $\beta$-chain and has been associated with polycythemia, this variant having been named $\mathrm{Hb}$ Coimbra from the town of Coimbra in Portugal where it was first described by Tamagnini et al. (1991).

In this paper we report the clinical and laboratory findings for three unrelated patients investigated for polycythemia at the University of Campinas (UNICAMP) Uni-

Send correspondence to Maria de Fatima Sonati. Universidade Estadual de Campinas, Faculdade de Ciências Médicas, Departamento de Patologia Clínica, Caixa Postal 6111, 13083-970 Campinas, SP, Brazil. E-mail: sonati@fcm.unicamp.br. versity Hospital, in Campinas, São Paulo state, southeastern Brazil. The definitive diagnosis for these patients could only be established after the presence of $\mathrm{Hb}$ Coimbra was demonstrated.

The patients were as follows: Patient 1. G.P.P., a 68-year-old female of German descent, was advised to undergo examination after routine laboratory tests revealed a high hematocrit (Hct) value. The patient had no health complaints and no other previously diagnosed diseases. At physical examination, only a ruddy facial color was observed and the cause of the elevated Hct value could not be determined. Hemoglobin electrophoresis and solubility and stability tests were all normal. However, $\mathrm{Hb}$ analysis by HPLC (Variant II, BioRad, USA) showed an abnormally enlarged peak in the $\mathrm{Hb}$ A position and the same HPLC profile was observed in the patient's 48 -year-old son, who was asymptomatic. Patient 2. A.T., a 49-year-old male of Portuguese ancestry sought health care because of pruritus, visual disturbances and an unusual red coloration of his cheeks, ears, nose and neck. He had been a regular blood donor for the previous 13 years, since phlebotomy made him feel better. Blood tests showed a high Hct and $\mathrm{Hb}$ investigation revealed a normal electrophoretic profile and a HPLC chromatogram similar to that observed in patient 1. Patient 3. R.H.C, a 13-year-old male of German descent who was initially referred to the Pediatrics Department presenting with impaired neuropsychomotor development due 
to congenital toxoplasmosis, and microcytic and hypochromic anemia (ferritin $=9.6 \mathrm{ng} \mathrm{mL}^{-1}$ ). The HPLC chromatogram of this patient and his mother was similar to those of patients 1 and 2. The hematological data on all these individuals are shown in Table 1.

Hemoglobin functional analyses were performed according to Rossi-Fanelli and Antonini, (1958). Since the variant could not be separated from normal $\mathrm{Hb} \mathrm{A}$, total hemolysate (in the stripped form and in the presence of organic polyphosphates) was analyzed. In a preliminary test, oxygen affinity, measured in the absence of anionic cofactors, was higher than that of stripped $\mathrm{Hb} \mathrm{A}$ : the $\mathrm{P}_{50}$ value was $0.76 \mathrm{~mm} \mathrm{Hg}$, while the $\mathrm{P}_{50}$ of $\mathrm{Hb} \mathrm{A}$ was $2.52 \mathrm{~mm} \mathrm{Hg}$, when studied under the same conditions $\left(\mathrm{pH} \mathrm{7.0,20}{ }^{\circ} \mathrm{C}\right)$. The Hill coefficient $(n)$ was reduced to about 1.5 at $\mathrm{pH} 7.0$; however, this $n$ value did not reflect cooperativity, since total hemolysate was used, i.e., a mixture of two hemoglobins of widely different oxygen affinities. Upon addition of organic phosphates (inositol hexaphosphate - IHP), the $\mathrm{P}_{50}$ value increased to $2.35 \mathrm{~mm} \mathrm{Hg}$ at $\mathrm{pH} 7.0$ (HbA $\mathrm{P}_{50}=32.0 \mathrm{mmHg}$ ), demonstrating a small change in oxygen affinity of the total hemolysate.

For molecular genetic analyses, genomic DNA was extracted from peripheral blood using the Blood Purification Kit (Invitrogen, Carlsbad, CA, USA). A 661 bp fragment of the $\beta$-globin gene (from position -140, relative to the Cap site, to position +521 , at the beginning of IVS-II) was amplified by the polymerase chain reaction (PCR) using the primers described by Miranda et al. (1997). Direct sequencing of the PCR products was performed using the BigDye $^{\mathrm{TM}}$ Terminator Cycle sequencing Kit and the ABI PRISM $^{\mathrm{TM}} 377$ Genetic Analyser (PE Applied Biosystems, Foster City-CA, USA). A single base substitution at codon 99 of the $\beta$-globin gene, corresponding to $\mathrm{Hb}$ Coimbra
$(\mathrm{GA} \underline{\mathrm{T}} \rightarrow \mathrm{GA} \underline{\mathrm{A}})$, was detected in heterozygosis in all individuals investigated (Patient 1 and her son, Patient 2, Patient 3 and his mother).

The $\beta$-globin gene cluster haplotypes were determined, by genotyping restriction fragment length polymorphisms (RFLPs) in and around the $\beta$-globin-like genes: Hind III - 5, ${ }^{\mathrm{G}} \gamma$, Hind III - 5, A $\gamma$, Hinc II - 5' $\psi \beta$, Hinc II 3' $\psi \beta, A v a$ II - 3' $\beta$ and BamH I - 3' $\beta$ (Antonarakis et al., 1982; Orkin et al., 1982; Sutton et al., 1989; Lee et al., 2002). The results are shown in Figure 1. The association between the $\beta$-haplotype (- - - - +) and the Hb Coimbra mutation could be established in Patient 3. Data on Patients 1 and 2 also make this association a possibility.

The nucleotide substitution (GAT $\rightarrow$ GAA) at the $99^{\text {th }}$ codon of the $\beta$-globin gene, detected in our patients is responsible for the previously described $\mathrm{Hb}$ Coimbra. This point mutation was first described in a Portuguese family (Tamagnini et al., 1991), and later in several members of a

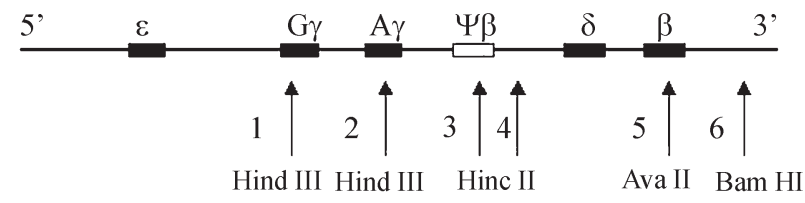

\begin{tabular}{|c|c|c|c|c|c|}
\hline Sites & Patient 1 & $\begin{array}{c}\text { Patient 1' } \\
\text { Son }\end{array}$ & Patient 2 & Patient 3 & $\begin{array}{c}\text { Patient 3's } \\
\text { mother }\end{array}$ \\
\hline 1 & $-/+$ & $-/-$ & $-/-$ & $-/-$ & $-/+$ \\
\hline 2 & $-/+$ & $-/-$ & $-/-$ & $-/-$ & $-/+$ \\
\hline 3 & $-/-$ & $-/-$ & $-/-$ & $-/-$ & $-/-$ \\
\hline 4 & $-/+$ & $-/-$ & $-/-$ & $-/-$ & $-/-$ \\
\hline 5 & $-/+$ & $-/+$ & $-/+$ & $-/-$ & $-/-$ \\
\hline 6 & $+/-$ & $+/-$ & $+/-$ & $+/-$ & $+/+$ \\
\hline
\end{tabular}

Figure 1 - Restriction sites at the $\beta$-globin gene cluster and the restriction fragment length polymorphism (RFLP) haplotypes found in the Hb Coimbra carriers.

Table 1 - Hematological data.

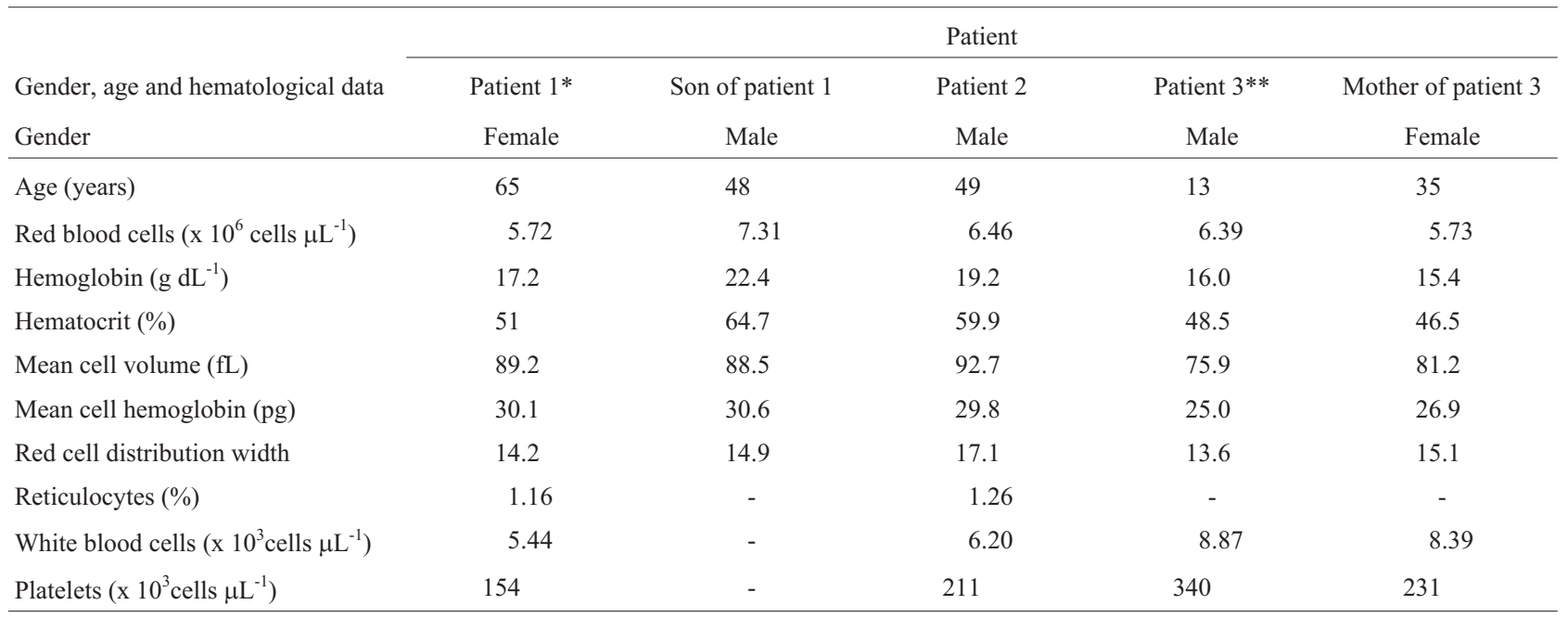

*Blood sample collected during treatment for phlebotomy.

**Blood sample collected during treatment for iron deficiency anemia. 
German family and in an American-German family in Michigan, USA (http://globin.cse.psu.edu). It is noteworthy that our Patients 1 and 3 have German ancestry, while Patient 2 was of Portuguese descent. The $\beta$-haplotype (- - - + ), common in normal Mediterranean populations (Orkin et al., 1982), was found to be associated with the mutation in Patient 3. Since it may also be the case in the other two patients, a common origin for this mutation in the three Brazilian families is a possibility. Data on the association of the $\beta$-haplotype and $\mathrm{Hb}$-Coimbra both in our population and in European families are not available.

Human $\mathrm{Hb}$ normally interacts with organic polyphosphates (Chanutin and Curnish, 1967). The physiological implication of the Asp $\rightarrow$ Glu in Hb Coimbra is the weakening of the interaction of anionic cofactor, leading to increased $\mathrm{Hb}$ synthesis in order to compensate for low tissues oxygenation (Reed et al., 1968; Nagai et al., 1982). Currently, seven mutations at the $399 \mathrm{Asp}$ are known: Hb Kempsey (Asp $\rightarrow$ Asn), Hb Yakima (Asp $\rightarrow$ His), Hb Radcliffe (Asp $\rightarrow$ Ala), Hb Ypsilanti (Asp $\rightarrow$ Tyr), Hb Hotel-Dieu (Asp $\rightarrow$ Gly), Hb Chemilly (Asp $\rightarrow$ Val) and $\mathrm{Hb}$ Coimbra (Asp $\rightarrow$ Glu) (http://globin.cse.psu.edu; Tamagnini et al., 1991). Variable degrees of oxygen affinity demonstrate a 25 to 60 percent decrease in the Bohr effect, and all cases were characterized clinically by erythrocytosis. Interestingly, despite the fact that Patient 3 and his mother had high erythrocyte counts they did not present high Hct levels or clinical complaints.

Our findings demonstrate the importance of investigating $\mathrm{Hb}$ variants when erythrocytosis is detected. Although conventional $\mathrm{Hb}$ electrophoresis did not show a distinctive profile for $\mathrm{Hb}$ Coimbra, the HPLC methodology allowed its detection. Functional studies and molecular analyses were also effective.

\section{Acknowledgements}

We thank the Fundação de Amparo à Pesquisa do Estado de São Paulo (FAPESP) for financial support (Grant 02/13801-7).

\section{References}

Antonarakis SE, Boehm CD, Giardinia PJ and Kazazian HHJr (1982) Nonrandom association of polymorphic restriction sites in the beta-globin gene cluster. Proc Natl Acad Sci USA 79:137-141.

Bunn HF and Forget BG (1986) Hemoglobin: Molecular, Genetics and Clinical Aspects. WB Saunders Company, Philadelphia, $690 \mathrm{pp}$.

Chanutin A and Curnish RR (1967) Effect of organic and inorganic phosphates on the oxygen equilibrium of human erythrocytes. Arch Biochem Biophys 121:96-102.

Park SS, Kim JY and Cho HI (2002) RFLP haplotypes of betaglobin gene complex of beta-thalassemic chromosomes in Koreans. J Korean Med Sci 17:475-478.

Miranda SRP, Fonseca SF, Figueiredo MS, Yamamoto M, Grotto HZW, Saad STO and Costa FF (1997) Hb Köln $\left[\alpha_{2} \beta_{2} 98\right.$ (FG) $\mathrm{Val} \rightarrow \mathrm{Met}$ ] identified by DNA analysis in a Brazilian family. Braz J Genet 20:745-748.

Nagai K, La Mar GN, Jue T and Bunn HF (1982) Proton magnetic resonance investigation of the influence of quaternary structure on the iron-histidine bonding in deoxy hemoglobins. Biochemistry 21:842-847.

Orkin SH, Kazazian HHJ, Antonarakis SE, Goff SC, Boehm CD, Sexton JP, Waber PG and Giardina PJ (1982) Linkage of beta-thalassemia mutations and beta-globin gene polymorphisms with DNA polymorphisms in human beta-globin gene cluster. Nature 296:627-631.

Reed CS, Hampson R, Gordon S, Jones RT, Novy MJ, Brimhall B, Edwards MJ and Koler RD (1968) Erythrocytosis secondary to high oxygen affinity of a mutant hemoglobin, hemoglobin Kempsy. Blood 31:623-632.

Rossi-Fanelli A and Antonini E (1958) Studies on the oxygen and carbon monoxide equilibria of human myoglobin. Arch Biochem Biophys 77:478-492.

Sutton M, Bouhassira EE and Nagel RL (1989) Polymerase chain reaction amplification applied to the determination of betalike globin gene cluster haplotypes. Am J Hematol 32:6669.

Tamagnini GP, Ribeiro ML, Valente V, Ramachandran M, Wilson JB, Baysal E, Gu LH and Huisman TH (1991) Hb Coimbra or alpha 2 beta (2)99(G1)Asp $\rightarrow$ Glu, a newly discovered high oxygen affinity variant. Hemoglobin 15:487496.

Associate Editor: Angela M. Vianna-Morgante 